\title{
VII. The H-theorem and the dynamical theory of gases
}

\section{J.H. Jeans M.A. F.R.S.}

To cite this article: J.H. Jeans M.A. F.R.S. (1906) VII. The H-theorem and the dynamical theory of gases, Philosophical Magazine Series 6, 12:67, 60-62, DOI: 10.1080/14786440609463512

To link to this article: http://dx.doi.org/10.1080/14786440609463512

曲 Published online: 16 Apr 2009.

Submit your article to this journal $\pi$

Q View related articles $\sqsubset$ 
Prof. Lorentz. Let us join a piece of real and a piece of ideal matter, so as to form a closed circuit. Let one of the junctions, $\mathrm{A}$, be a perfect conductor of heat devoid of radiating power, while each face of the other junction $B$ is a perfect radiator, devoid of conducting power. Let all the rest of the surfaces of both $R$ and $I$ be supposed impervious to energy.

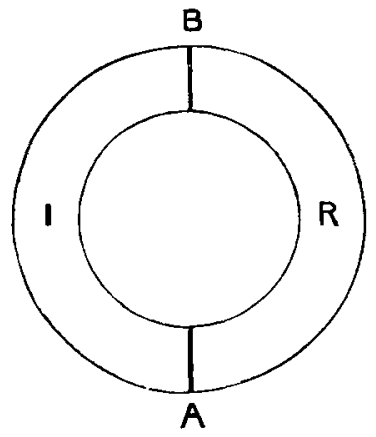

If junction $A$ is thrown out of action the bodies $R, I$ will as before assume different temperatures. If junction $B$ is thrown out of action the temperatures will equalise by conduction of heat across $\mathbf{A}$. If both junctions are in operation at once, we shall get a continuous flow of energy round the circuit in the direction I A R B, and a continuons rise of temperature as we pass through $I$ from $B$ to $A$, or through $R$ from $A$ to $B$.

These difficulties do not cast suspicion on the validity of the second form of the theory of radiation, which begins by presupposing a flow, rather than equilibrium, of energy, but to the present writer they seem fatal to the thermodynamical theory.

Princeton, N.J., April 24.

VII. The H-Theorem and the Dynamical Theory of Gases. By J. H. Jeans, M.A., F.R.S., Professor of Applied Mathematics in Princeton University *

TN the Phil. Mag. for April (pp. 455-465), Mr. Burbury 1 again discusses my work on the Theory of Gases. While grateful for parts of his discussion which seem to be sympathetic and appreciative, I recognize that on the main question at issue Mr. Burbury is still inclined to disagree in toto with my views.

* Communicated by the Author. 
The aim of my work was not to restate the results of former writers in a new or simplified notation (without, as Mr. Burbury says, "in any way altering the lngical position of the Kinetic Theory")." My aim was to give a new discussion of the whole question, based on no physical foundations except the laws of dynamics. This I believe to be possible. The molecules of a gas have probably never heard of Mr. Burbury's Assumption A, or been warned to remain "molekular-ungeordnet." But by passive obedience to the laws of dynumies, they arrange themselves in some definite way. The mathematician, from a knowledge solely of the laws of dynamics, ought to be able to follow the motion of the molecules and calculate their final arrangement.

This is the problem which I have tried to solve. Mr. Burbury states clearly that he thinks I bave failed; while $I$, to be quite frank, still think I have succeeded. I cannot, therefore, let Mr. Burbury's article pass without reply.

I do not find that Mr. Burbury brings any new charges against my work, beyond those which he has brought in previous articles*; and to these I have already replied $\dagger$. I will confess, however, that I bave found a generality and vagueness about these charges, which makes them difficult to refute satisfactorily. If, as Mr. Burbury seems to think, my argument is wholly unsound, he can surely pick out one delinite point and say: "Here, at this particular point, you introduce an assumption from outside your premisses"; or, "Here, in this particular statement, your logic is at fault." Or if, as Mr. Burbury perhaps thinks, the number of weak points is legion, I ask him to pick out the weakest one, and concentrate his attack on that-only one link need be broken to destroy a chain. I cannot, witbin reasonable limits of space, defend a whole theory against vague expressions of opinion, or against a general condemnation, unsupported by specific arguments.

Meanwhile may I reply to those two of Mr. Burbury's objections, which I understand most clearly?

OBJECTION I. "The real defect... in every proof yet given of Maxwell's Law, consists in my opinion in this, that it ignores the continuity of the motion altogether."

Answer. Continuity of motion enters most proofs, including my own attempted proof, through the dynamical equations of motion. In fact, these equations simply express that the continuity assumed by the theory is of the kind observed in nature. 
OBJECrION II. "If the new method leads, or appears to lead, to any physical results not attainable by the ordinary method, that can only be because along with the new method, we have introduced some new hypothesis unawares."

Axswer. In point of fact the physical result is attainable by the ordinary method. For " $\rho$ "let Mr. Burbury read" totul number of systems for which the variables $x_{a}, y_{a}, \hat{z}_{a}, x_{b}, \ldots u^{\prime}$ lie between the limits $x_{a}$ and $x_{a}+d x_{a}, y_{a}$ and $y_{a}+d y_{a}, z_{a}$ and $z_{a}+d z_{a}, x_{b}$ and $x_{b}+d x_{b}, \ldots v_{n}$ and $w_{n}+d w_{n}$, divided by $d x_{a} d y_{a} d z_{a} d x_{b} \ldots d u_{n}, " \& c .$, and the result will have been attained, although perhaps without inuch elegance or conciseness.

But if the ultimate test of any "physical result" is to be whether or not it is attainable by the "ordinary" method, then let physicists be warned against new methods, and let us admit that Nature herself must be "introducing a great many bypotheses unawares."

Princeton, N.J.

VIII. Letter from Mr. BARB FR STAKKEY describing remarkable results of a Discharge of Lightning upon an Oak-Tree; with Note by Lord KeLviN.

DEAR LORD KeLVIN, June 4th, 1900.

A BOUT 5 o'clock on the afternoon of August 29th last. A year during a severe thunderstorm, three Oak-trees were struck in the Park; and in one case the effect on the tree was so remarkable that I think I ought to describe it to you. A large number of shreds of wood, probably not fewer than two or three dozen, and varying from 1 to 3 feet in length, and of an irregular breadth of $\frac{i}{6}$ to $\frac{1}{4}$ of an inch, were tor'll out of the bole of the tree, and remained with one end fixed in the ground to a depth of 1 inch or more, standing in a more or less nearly vertical position inclined towards the tree, at a distance of about 15 feet from the bole of the tree on the west side. These irregular shreds were so light and flexible that the act of falling could not have placed them in the position described. Apparently they had been sucked into the ground. Could this have been caused by any electrical action?

When I visited the tree a few days ago, I still found one of these shreds embedded in the ground.

I am, Yours very truly,

W. I. S. Barber Starkey. 